\title{
Elliptical double corrugated tubes for enhanced heat transfer
}

\author{
Navickait, Kristina; Cattani, Luca; Bahl, Christian R.H.; Engelbrecht, Kurt
}

Published in:

International Journal of Heat and Mass Transfer

Link to article, DOI:

10.1016/j.jjheatmasstransfer.2018.09.003

Publication date:

2018

Document Version

Peer reviewed version

Link back to DTU Orbit

Citation (APA):

Navickait, K., Cattani, L., Bahl, C. R. H., \& Engelbrecht, K. (2018). Elliptical double corrugated tubes for enhanced heat transfer. International Journal of Heat and Mass Transfer, 128, 363-377.

https://doi.org/10.1016/j.ijheatmasstransfer.2018.09.003

\section{General rights}

Copyright and moral rights for the publications made accessible in the public portal are retained by the authors and/or other copyright owners and it is a condition of accessing publications that users recognise and abide by the legal requirements associated with these rights.

- Users may download and print one copy of any publication from the public portal for the purpose of private study or research.

- You may not further distribute the material or use it for any profit-making activity or commercial gain

- You may freely distribute the URL identifying the publication in the public portal

If you believe that this document breaches copyright please contact us providing details, and we will remove access to the work immediately and investigate your claim. 


\title{
Elliptical double corrugated tubes for enhanced heat transfer
}

\author{
Kristina Navickaite $\dot{1}^{1 *}$, Luca Cattani ${ }^{2}$, Christian R. H. Bahl ${ }^{1}$, Kurt Engelbrecht ${ }^{1}$
}

${ }^{1}$ Department of Energy Conversion and Storage, Technical University of Denmark, Frederiksborgvej 399, 4000 Roskilde, Denmark

CIDEA, Interdepartmental Centre, University of Parma, Parco Area delle Scienze 181/A, I-43124 Parma, Italy

*knav@dtu.dk

Abstract. The thermal performance at constant pumping power conditions was numerically investigated in ellipse and super ellipse-based double corrugated tubes. A significant increase in thermal efficiency in double corrugated tubes is accompanied with a reasonable penalty in flow reduction for the cases modelled. An ellipse and a super ellipse-based double corrugated tubes were modelled at laminar fully hydraulically developed incompressible flow. Each base geometry was analysed holding either hydraulic diameter constant or the cross-sectional area constant. The pressure drop was normalized to the length of each modelled tube in order to maintain the pumping power. Thermal analysis was conducted under constant wall temperature boundary condition. The governing equations for nonisothermal flow were solved using the finite element method, and the results of the simulations were normalized to an equivalent straight tube. Numerical results predict a thermal efficiency enhanced by $400 \%$ maintaining 4.2 times lower volumetric flow rate in double corrugated tubes at the same pressure drop. The global performance evaluation criterion increases up to $14 \%$ for the double corrugated tubes with an ellipse-base and up to $11 \%$ for the tubes with super ellipse-base.

Keywords: heat transfer enhancement, pressure drop, numerical simulation, corrugated tube, performance evaluation criteria

\section{Nomenclature}

\begin{tabular}{|l|l|}
\hline \multicolumn{2}{|l|}{ Variables } \\
\hline$A_{s}$ & Surface area, $\mathrm{m}^{2}$ \\
\hline$A_{c}$ & Cross-section area, $\mathrm{m}^{2}$ \\
\hline$A R$ & Aspect ratio \\
\hline$a, b$ & Semi-major and semi-minor axes of an ellipse, $\mathrm{m}$ \\
\hline$C$ & Heat capacity rate, $\mathrm{W} \mathrm{K}^{-1}$ \\
\hline$c_{p}$ & Specific heat, $\mathrm{J}(\mathrm{kg} \mathrm{K})^{-1}$ \\
\hline$D$ & Diameter, $\mathrm{m}$ \\
\hline$f$ & Friction factor, [-] \\
\hline $\bar{h}$ & Average local convection coefficient, $\mathrm{W}\left(\mathrm{m}^{2} \mathrm{~K}\right)^{-1}$ \\
\hline$k$ & Thermal conductivity of water, $\mathrm{W}(\mathrm{m} \mathrm{K})^{-1}$ \\
\hline$\dot{m}$ & Mass flow rate, kg $\mathrm{s}^{-1}$ \\
\hline$n$ & Ellipse shape factor, [-]; unit normal to the surface \\
\hline$N T U$ & Number of transfer units, [-] \\
\hline$N u$ & Nusselt number, [-] \\
\hline$P$ & Perimeter, $\mathrm{m}$ \\
\hline$P r$ & Prandtl number, [-] \\
\hline$p$ & Corrugation period, $\mathrm{m}$ \\
\hline$P E C$ & Performance evaluation criteria, [-] \\
\hline$q$ & Heat transfer, $\mathrm{W}$ \\
\hline$R$ & Radius, $\mathrm{m}$ \\
\hline$R e$ & Reynolds number, [-] \\
\hline $\bar{U}$ & Average overall heat transfer coefficient, $\mathrm{W}\left(\mathrm{m}^{2} \mathrm{~K}\right)^{-1}$ \\
\hline$U, u$ & Fluid velocity in $x$ direction, $\mathrm{m} \mathrm{s}^{-1}$ \\
\hline$x, y, z$ & Geometric coordinates, $\mathrm{m}$ \\
\hline$\dot{V}$ & Flow rate, $\mathrm{m}^{3} \mathrm{~s}^{-1}$ \\
\hline$\Delta T$ & Temperature difference, $\mathrm{K}$ \\
\hline & \\
\hline & \\
\hline$P$ &
\end{tabular}

\begin{tabular}{|l|l|}
\hline$\Delta T_{l m}$ & Logarithmic mean temperature difference, $\mathrm{K}$ \\
\hline$\Delta p$ & Pressure difference, $\mathrm{Pa}$ \\
\hline Abbreviations \\
\hline AEA & Alternating elliptical axis \\
\hline BC & Boundary conditions \\
\hline BL & Boundary layers \\
\hline CFD & Computational fluid dynamics \\
\hline err & Error \\
\hline Greek letters \\
\hline$\varepsilon$ & Effectiveness, [-] \\
\hline$\gamma$ & Geometric surface equation \\
\hline$\Theta$ & Temperature difference, $\mathrm{K}$ \\
\hline$\mu$ & Dynamic viscosity, Pa s \\
\hline$\rho$ & Density, kg $\mathrm{m}^{-3}$ \\
\hline Subscripts \\
\hline $\mathrm{c}$ & Coarse \\
\hline conv & Convective \\
\hline $\mathrm{f}$ & Fine, fluid \\
\hline $\mathrm{h}$ & Hydraulic \\
\hline $\mathrm{i}$ & Inlet \\
\hline $\mathrm{m}$ & Mean \\
\hline max & Maximum \\
\hline min & Minimum \\
\hline $\mathrm{s}$ & Surface \\
\hline $\mathrm{o}$ & Outlet \\
\hline 0 & Straight (reference) \\
\hline
\end{tabular}




\section{Introduction}

Enhanced heat transfer techniques are of interest for many different industrial fields, from the food industry all the way to aerospace engineering [1-5]. These techniques are particularly interesting for industrial applications in which the thermal processing of medium and high viscosity fluids is required. Moreover, in many cases, the fluid flow is necessarily laminar and therefore the efficiency of the heat transfer apparatuses in which fluids are conveyed is inevitably penalized. Techniques producing enhanced heat transfer accompanied by reduced pumping power are in high demand in these industries. Improved heat transfer allows thermodynamic cycles to operate at conditions that are more efficient and opens new opportunities for alternative cycles and sustainable energy technologies.

Heat transfer enhancement techniques essentially reduce the thermal resistance by increasing the heat transfer coefficients with or without an increase of the heat transfer surface area. The benefits that can be derived are, for instance, the reduction of the size of the heat exchangers which can reduce cost, and the decrease of the temperature difference at which the working fluids operate which increases thermal performance or efficiency. The literature suggests to classify the techniques of enhanced heat transfer into active techniques that require a mechanical aid or electrostatic fields, passive techniques that do not require an external power and compound techniques that represent the combination of two or more different techniques [1]. Passive techniques are based on changes induced on the fluid flow through geometrical disruptions or modification of the surface, such as curvature of the walls or surfaces roughness or corrugation or through the insertion of devices in the main flow directly or by means of additives $[1,6]$. Since these techniques do not require any external power input, they are of great interest for industrial applications. Moreover, in the case of renovation or modification of an existing heat exchanger, the passive techniques offer much faster and easier solutions compared to active techniques. In addition, manufacturing process of realization of insertion or particular shape modifications of a tube wall is quite simple and nowadays it is a mature technology.

For all those reasons, the passive techniques became the most frequently employed for engineering applications, such as rippled and spirally corrugated tubes in systems for domestic hot water preparation using solar energy, finned tube geometries, treated surfaces, rough surfaces, displaced enhancement devices, swirl-flow devices, surface-tension devices, coiled tubes, or flow additives [1]. One of the most widely adopted passive technique is wall corrugation: the enhancement effect associated with wall corrugation is due to the periodic interruption of the development of both the thermal and hydraulic boundary layers, an increase in heat transfer area, generation of swirling and/or secondary flows and the promotion of flow transition to an unsteady regime. They are employed in a high number of industrial applications. It has also been emphasized that corrugated tubes give an advantage for more rapid thermal food processing which is important for retaining natural and organic properties of food [7].

The main research efforts over the last five years have been focused on investigating spirally or transversally corrugated tubes and channels, fins or inserts of wavy strip tapes, and other techniques that allow disturbance of thermal boundary layers [8-16]. A concept of fluted tubes was investigated by Srinivasan et al. [12]. The definition of the shape of the cross-section of the fluted tubes was given by bore and envelope diameters, flute depth, pitch and the helix angle, which depends on the number of flute starts. Most of the investigated corrugated tubes have a non-circular cross-section, e.g. a triangle shaped cross-section or a star shaped cross-section.

Another method to increase heat transfer was presented by Guo et al. [17], who suggested that convection can be enhanced by increasing the included angle between the fluid velocity and the temperature gradient. In other words, the thermal gradient in the radial direction must be forced to be more perpendicular to the velocity profile in the flow direction. This means that the mixing of the flow should be ensured in the radial direction. This can be done by changing the boundaries of the fluid channel, and an implementation of the principles suggested by Guo et al. [17] is an alternating elliptical axis geometry (AEA) tube where the flow geometry transitions from an elliptical cross section at a specific angle to an elliptical cross section at another angle. Li et al. [18] demonstrated that AEA tubes give at least an $84 \%$ increase in heat transfer compared to a straight tube. Khaboshan and Nazif [13] performed modelling of AEA tubes for turbulent flow and showed that the tubes have an enhanced heat transfer performance at a performance evaluation criterion that is above 1 for some flow ranges. Meng et al. [19] proved experimentally that the heat transfer is $100-500 \%$ enhanced in AEA tubes for the Reynolds number $(R e)$ region from 500 to 2300 with a $100-350 \%$ increase in flow resistance. Moreover, 
the Authors proposed uniform correlations for Nusselt number $(\mathrm{Nu})$ and friction factor $(f)$ in a range of $R e$ from 500 to 50000 for AEA tubes that have period and diameter ratio of $p / D=2$. The uniform correlation of $\mathrm{Nu}$ shows that the AEA tubes exhibits early transition from laminar to turbulent flow regime.

Generally, the geometries presented in literature show an increase in $N u$ with increasing $R e$ within the laminar flow regime. Research on more intensive ways to disrupt the thermal boundary layer has also been carried out. These methods include artificially increased wall roughness and different types of inserts or turbulators [20]. All the approaches discussed above increase the surface area for the heat transfer, the convection coefficient, and the pressure drop. The major attention of experimental and numerical work has been directed toward spirally corrugated tubes. Very few studies have reported results of global performance obtained using tubes, shaped in a sinusoidal manner [3,21,22]. Moreover, fewer results of experimental and modelling studies were obtained at low $R e$ [22-28]. Generally, it was found that a significant increase in heat transfer in a corrugated tube of a given geometry is obtained in a certain range of Re number and further raising $R e$ does not influence heat transfer as much. Hærvig et $a l$. [3] reported that increasing the corrugation length in spirally corrugated tubes increases $N u$. The same study also showed that at intense corrugations, the flow is radically different, which results in a slight increase in heat transfer, while pressure loss increases significantly.

In this paper, a novel geometry of a tube that is corrugated in both the transverse and annular directions, such that the hydraulic diameter $\left(D_{\mathrm{h}}\right)$ or cross-sectional area $\left(A_{c}\right)$ at any point in the flow direction is constant is presented. Double corrugated tubes with either an ellipse-based or a super ellipsebased cross-section were analysed. The concept is similar in principle to AEA tubes, but the transition between cross sectional profiles occurs continuously along the flow direction, which can give a lower pressure drop while maintaining an enhanced heat transfer performance. The variation of channel aspect causes the tube walls to constantly impinge and disturb the thermal boundary layer and enhance heat transfer.

The approach of maintaining a constant cross-sectional area was suggested by, for example, Jantsch [29]. In the case of a constant cross-section area, the average fluid velocity is constant while the pressure drop profile can vary along the flow direction. When the hydraulic diameter is held constant, the effective flow opening remains constant but the flow area can change along the flow direction, thus the average fluid velocity varies in the flow direction. CFD (Computational fluid dynamics) simulations are extensively used to predict thermohydraulic performance of enhanced geometries. Numerous studies have been published discussing performance of enhanced geometries in different flow regimes or thermal boundary conditions. In this study, CFD is used as a tool to predict the thermo-hydraulic performance of the double corrugated tubes in a laminar flow regime with temperature at the inner wall of the tube and the pressure drop held constant. Many engineering applications exchange energy with a low temperature heat source, such as a heat pump. Thus, a low inlet temperature $\left(T_{\mathrm{h}}\right)$ was selected as an input parameter. In order to predict thermal performance and reduction in flow rate study based on CFD modelling was conducted. The results are presented for double corrugated tubes that are ellipse or super ellipse-based, and each for constant cross-sectional area and constant hydraulic diameter. All simulations were run for an equivalent tube diameter of $5 \mathrm{~mm}$, with varying corrugation periods and aspect ratio of the flow area. All simulations were conducted in the laminar flow regime. A straight tube was modelled for comparison. Note that the fluid flow regime was determined and the Re number was calculated for a straight tube if not stated otherwise.

\section{Corrugation geometry}

The double corrugated tubes were designed in SolidWorks using the Parametric equation tool to define the longitudinal surface of the analysed geometries. The Lofted Boss/Base feature was used to create a solid body where the parametric equation defined the two axes of a double corrugated tube. The analysed tubes are based on an ellipse or super ellipse-based cross-section that changes aspect in the flow direction while maintaining either a constant $D_{\mathrm{h}}$ or constant $A_{c}$ along the $z$-axis. The double corrugated tubes with the constant $D_{\mathrm{h}}$ and an elliptical cross-section were reported previously in [30]. The cross-section of the corrugated tubes at any point in the flow direction is defined as an ellipse or a super ellipse with one axis equal to $x$ and the other equal to $y$. Note, that the $x$ and $y$ axes periodically become equal, forcing the cross-section to be either a circle (ellipse-based), or an absolutely symmetrical 
super ellipse (super ellipse-based). Eq. 1 gives the general canonical expression of the cross section in Cartesian coordinates. The parametric version of this equation was used for constructing the tubes in SolidWorks.

$$
\left|\frac{x}{a}\right|^{n}+\left|\frac{y}{b}\right|^{n}=1
$$

Here $a$ and $b$ are the semi-major and semi-minor axes of the ellipse respectively. $n$ is an ellipse shape factor. When $n=2$, the shape becomes an ordinary ellipse, when $\mathrm{n}>2$, the shape becomes a super ellipse. In this work, $n=2.5$ is chosen as it gives a good representation of the concept of a super ellipse.

The Lofted Boss/Base feature creates a solid body for Guide curves (surface equations (Table 1)) only if Profile (the start and end shapes) is given. Note, that an option to draw an ordinary ellipse already exists in SolidWorks. Thus, a modified Eq.1 is used only for drawing a super ellipse as a Profile of the tubes with a super ellipse-base. Here, Eq. 1 is multiplied by $\gamma=0.963$ in order to obtain values of $D_{\mathrm{h}}$ and $A_{\mathrm{c}}$ closer to the circle that has an equivalent $R$.

The equations used to approximate the surfaces of double corrugated tubes are given in Table 1. They define the geometry of a tube along the flow direction, $z$, corrugated in the $x$ and $y$ directions. The given equations approximate the surface of double corrugated tubes with a maximum of $\pm 4 \%$ deviation from the assumption of constant hydraulic diameter or cross-sectional area. However, SolidWorks approximates the given surface equations within a certain accuracy as well. The measured maximum deviation from the target $D_{\mathrm{h}}$ and $A_{\mathrm{c}}$ values is $\pm 4 \%$ and $\pm 5 \%$, respectively for the most corrugated tubes. The inaccuracy decreases with an increase in period $(p)$ or decrease in aspect ratio $(A R)$. Therefore, the tubes modelled here only approximate the desired geometry, but are considered to do so within an acceptable limit.

Table 1. The equation set for different analysed double corrugated tubes configuration.

\begin{tabular}{|c|c|c|c|}
\hline Type & Starting shape & Constant hydraulic diameter & Constant cross-sectional area \\
\hline $\begin{array}{c}\text { Ellipse- } \\
\text { base }\end{array}$ & & $\left\{\begin{array}{c}x=\frac{R}{2} A R^{\left(\sin \left(\frac{2 \pi}{p} z\right)\right)}+\frac{R}{2} \\
y=\frac{R}{2} A R^{\left(-\sin \left(\frac{2 \pi}{p} z\right)\right)}+\frac{R}{2}\end{array}\right.$ & $\left\{\begin{array}{l}x=R\left(A R^{\left(\sin \left(\frac{2 \pi}{p} z\right)\right)}\right) \\
y=R\left(A R^{\left(-\sin \left(\frac{2 \pi}{p} z\right)\right)}\right)\end{array}\right.$ \\
\hline $\begin{array}{l}\text { Super } \\
\text { ellipse- } \\
\text { base }\end{array}$ & & $\left\{\begin{array}{c}x=\left(\frac{R}{2} A R^{\left(\sin \left(\frac{2 \pi}{p} z\right)\right)}+\frac{R}{2}\right) \gamma \\
y=\left(\frac{R}{2} A R^{\left(-\sin \left(\frac{2 \pi}{p} z\right)\right)}+\frac{R}{2}\right) \gamma\end{array}\right.$ & $\left\{\begin{array}{l}x=\left(R\left(A R^{\left(\sin \left(\frac{2 \pi}{p} z\right)\right)}\right)\right) \gamma \\
y=\left(R\left(A R^{\left(-\sin \left(\frac{2 \pi}{p} z\right)\right)}\right)\right) \gamma^{(5)}\end{array}\right.$ \\
\hline
\end{tabular}

In the above reported equations, $R$ is the radius of an equivalent straight tube. The constant $\gamma=$ 0.963 is used to ensure the same cross-section and hydraulic diameter of the ellipse and super ellipse tubes based on the same value of $\mathrm{R}$. The cross-sectional area of a super ellipse-based tube is a quadratic function of $\gamma$, while the perimeter, of super ellipse-based tubes is a linear function of $\gamma$. Thus, the hydraulic diameter becomes a linear function of $\gamma$. Therefore, a single $\gamma$ coefficient is used to generate the geometry of super ellipse-based tubes for both constant $D_{\mathrm{h}}$ and constant $A_{\mathrm{c}}$.

Figure 1 (a) shows changes in the aspect ratio of ellipse-based double corrugated tubes with $D_{\mathrm{h}}$ held constant and $p=7.5 \mathrm{~mm}$. Figure 1 (b) shows the changes in aspect ratio of ellipse-based double corrugated tubes with $A_{\mathrm{c}}$ held constant and $p=7.5 \mathrm{~mm}$. 
(a)
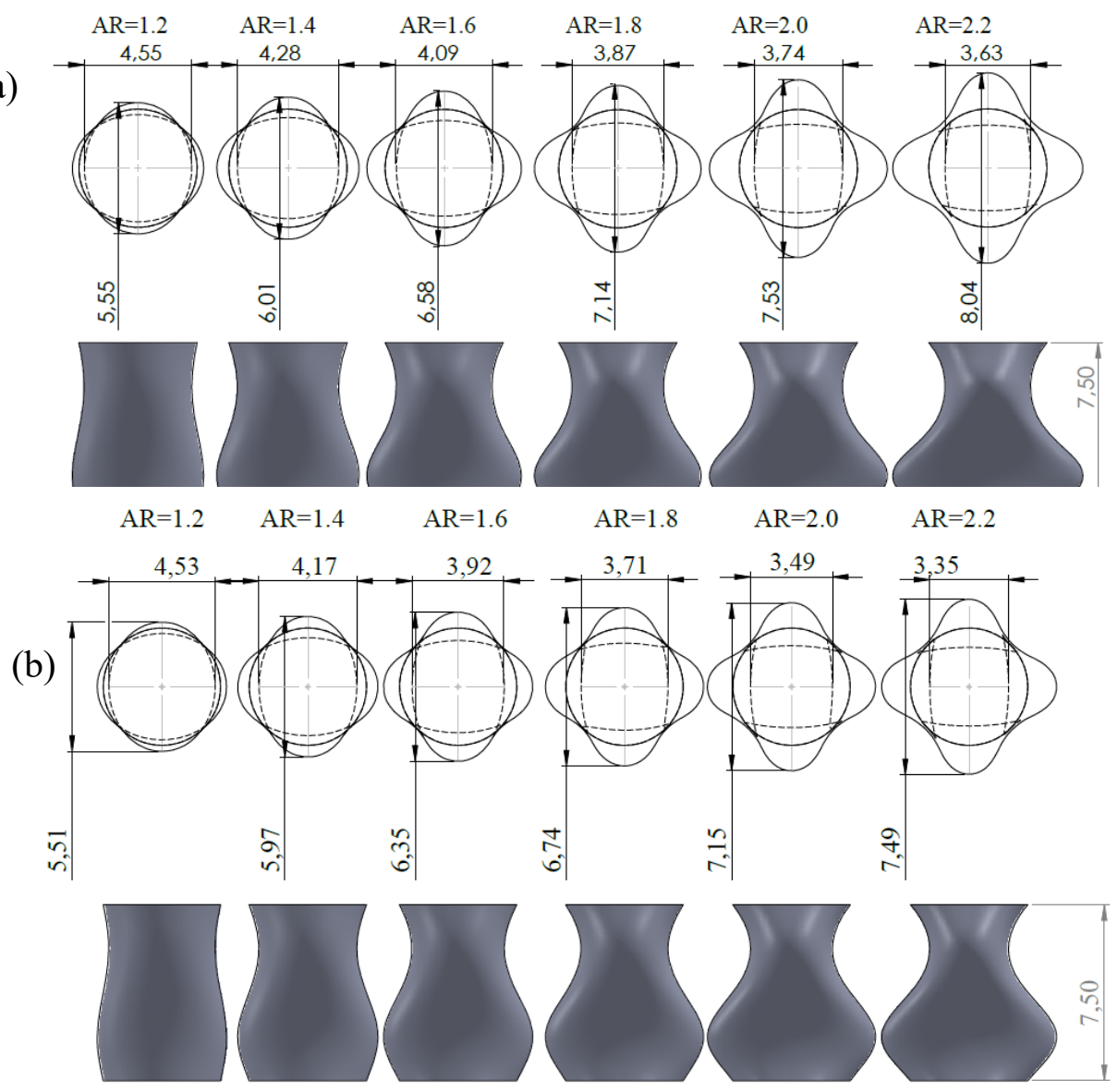

Figure 1. The ellipse-based double corrugated tubes with the hydraulic diameter $\left(D_{\mathrm{h}}\right)$ held constant (a) the constant cross-sectional area $\left(A_{\mathrm{c}}\right)(\mathrm{b})$. Dimensions are given in $\mathrm{mm}$.

Comparing Figure 1 (a) and (b), one can see that the double corrugated tubes with the constant $D_{\mathrm{h}}$ are more hydraulically rough than tubes with the constant $A_{\mathrm{c}}$. This is because tubes with the constant $A_{\mathrm{c}}$ have smoother surface transition between the extreme points.

\section{Model validation and the method of analysis}

\subsection{Mathematical formulation}

Fully hydraulically developed incompressible laminar flow with constant fluid properties was assumed for all modelled cases. A constant surface temperature at the inner wall of the tube and a constant pressure drop in the flow direction were implemented into the COMSOL Multiphysics environment. The double corrugated geometries were compared with the straight tube holding the length of the tubes constant rather than the surface area. Note, that the corrugations increase the surface area.

Patankar et al. [31] and Hærvig et al. [3] showed that one period of the geometry of interest is sufficient for numerical investigation of heat transfer enhancement when fully thermally and hydraulically developed flow is analysed. However, the flow analysed in this study is only hydraulically fully developed and periodic boundary conditions (BCs) could be applied only for the velocity field. In order to confirm that one period of a double corrugated tube is sufficient for thermal analysis of $1,3,4$ and 6 periods of ellipse-based tube with $D_{\mathrm{h}}$ constant, $A R=1.6$ and $p=7.5 \mathrm{~mm}$ were modelled as well as several different lengths of a straight tube. The obtained results were analysed as explained in 3.3. Method of analysis. Knowing the average local convection heat transfer coefficient $(\bar{h})$ at the outlets of the double corrugated tube with 6 periods and the straight tube with a length of $50 \mathrm{~mm}$, the outlet temperatures $\left(T_{0}\right)$ for fewer periods or shorter straight tubes were calculated by integrating from the tube inlets to a point of interest $l$ within the tube length. Figure 2 shows the comparison of calculated and modelled values for the double corrugated tube with $D_{\mathrm{h}}$ constant, $A R=1.6$ and $p=7.5 \mathrm{~mm}$ and the straight tube at different number of periods (length). Generally, calculated and modelled values show a good agreement. Note that higher calculated temperature differences $\Theta$ for smaller lengths were obtained 
due to the nature of the heat transfer problem. The temperature in thermal entrance region decays exponentially with distance. Also the values of $\bar{h}$ are much higher at the tube inlets than at the outlets, thus the theoretical calculations could provide only a general overview. Since the generally good agreement between calculated values and modelling results was obtained for the corrugated and the straight tubes, it is proved that one period of a double corrugated tube or a corresponding length of a straight tube is sufficient to use for numerical analysis.

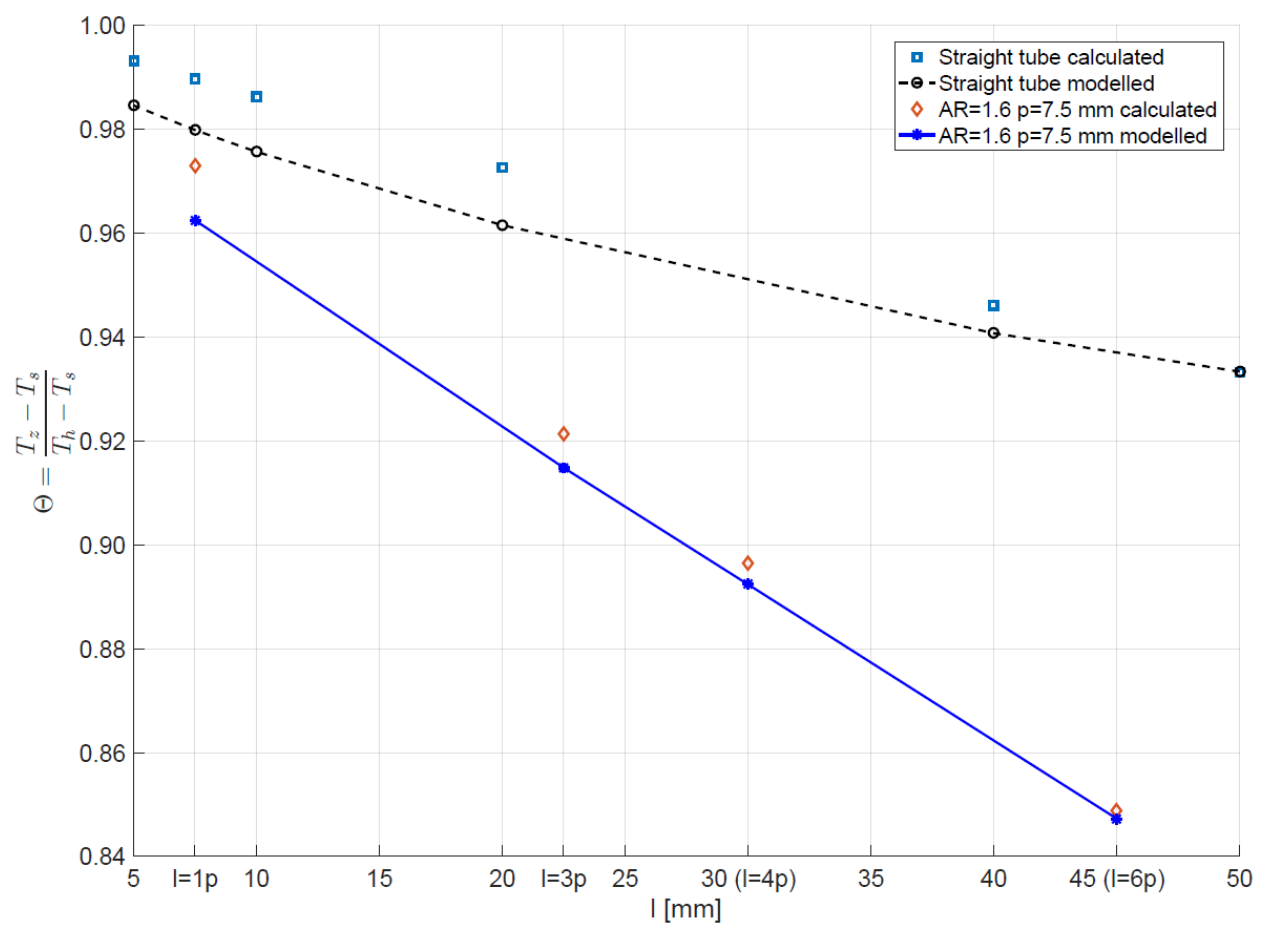

Figure 2. Temperature difference at the outlet of an ellipse-base double corrugated tube with $D_{\mathrm{h}}$ constant, $A R=1.6$ and $p=7.5 \mathrm{~mm}$ and a straight tube at different modelled number of periods or lengths.

In order to make the simulations less computationally expensive, a quarter of the fluid volume of one period of each tube was modelled. Therefore, the symmetry boundary condition was applied on the grey sections shown in Figure 3. The inlet $\left(T_{\mathrm{i}}\right)$ is marked green and the tube wall is marked blue $\left(T_{\mathrm{s}}\right)$, the outlet of the tube is an opposite wall to the inlet (yellow). The pressure drop was normalized by corrugation length. Boundary conditions and thermo-physical properties of the modelled fluid are given in Table 2.

Table 2. Fluid properties and flow conditions used in the modelling.

\begin{tabular}{|c|c|c|c|c|}
\hline$R,[\mathrm{~mm}]$ & $\rho,\left[\mathrm{kg} \mathrm{m}^{-3}\right]$ & $\Delta p / l,\left[\mathrm{~Pa} \mathrm{~m}^{-1}\right]$ & $T_{\mathbf{i},[\mathbf{K}]}$ & $T_{\mathrm{s}}[\mathrm{K}]$ \\
\hline 2.5 & 1000 & {$[246 ; 164 ; 82 ; 16]$} & 303 & 281 \\
\hline$c_{\mathrm{p}},\left[\mathrm{J}(\mathrm{kg} \mathrm{K})^{-1}\right]$ & $v,\left[\mathrm{~m}^{2} \mathrm{~s}^{-1}\right]$ & $\mu,[$ Pa s] & $k,\left[\mathbf{W}(\mathbf{m ~ K})^{-1}\right]$ & $\boldsymbol{P r},[-]$ \\
\hline 4183 & $8 \mathrm{e}-7$ & 8 e- 4 & 0.603 & 5.5 \\
\hline
\end{tabular}

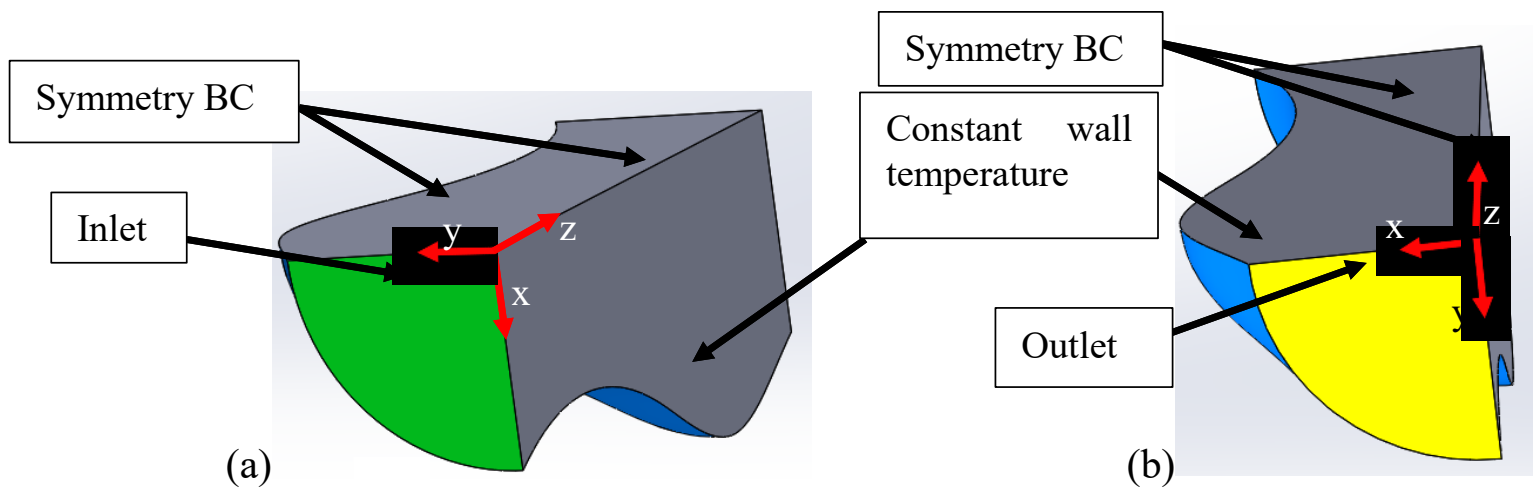

Figure 3. Visualization of the boundary conditions applied on the modelled geometries. The inlet water temperature is marked in green, constant surface temperature is marked in blue. The symmetry boundary conditions are applied on the walls marked in grey. The outlet is opposite to the green boundary. Pressure gradient condition is applied on the inlet (green (a)) and outlet (yellow (b)). 


\subsection{Mesh selection and model validation}

All the modelled tubes were meshed using a swept mesh with tetrahedral elements and two boundary layers (BL). The Nusselt number $N u$ is selected as a control quantity for the mesh evaluation. It is well known that BLs are necessary to model fluid flow more precisely and obtain more accurate values of a velocity gradient near the wall. Thus, the simulation results of a straight tube model with two, five, seven and ten BLs were analysed to find out whether two BLs are sufficient. Also, four different sizes of meshes for each type of geometry with the element density from 1206 to 4030 elements $/ \mathrm{mm}^{3}$ were analysed. The element density was used as a consistent comparison method of meshes of all the studied tubes since the volume of the tubes varies with corrugation height and length. Relative errors (err) of the control quantities were calculated as described in Eq. 6 [28].

$$
\text { err }=100\left|\frac{N u_{c}-N u_{f}}{N u_{f}}\right|
$$

Where: subscripts $c$ and $f$ denote the coarsest (fewest BLs) and the finest (most BLs) meshes, respectively.

Increasing the number of BLs above two did not show a significant difference in the simulations results, the err was $0.006 \%$, only the computational time had increased, showing that two BLs were sufficient. The relative errors in using the finest and the selected mesh were less than $0.5 \%$ suggesting that the accuracy of numerical models, when the selected mesh used, is acceptable. Note that mesh independency studies were carried out for all four types of double corrugated tubes separately and only the summarized conclusion is given. Moreover, Figure 4 shows that the result of the mesh independency study follow asymptotical behaviour, thus it was concluded that the study is mesh independent when a mesh finer than 2000 elements per $\mathrm{mm}^{-3}$ was used. Additionally, numerical results of a straight tube agree with the analytical solution [30]. Thus, the model was proved to be valid. Figure 5 shows the isometric view of a quarter of a cross-section of a double corrugated tube after being meshed in COMSOL.

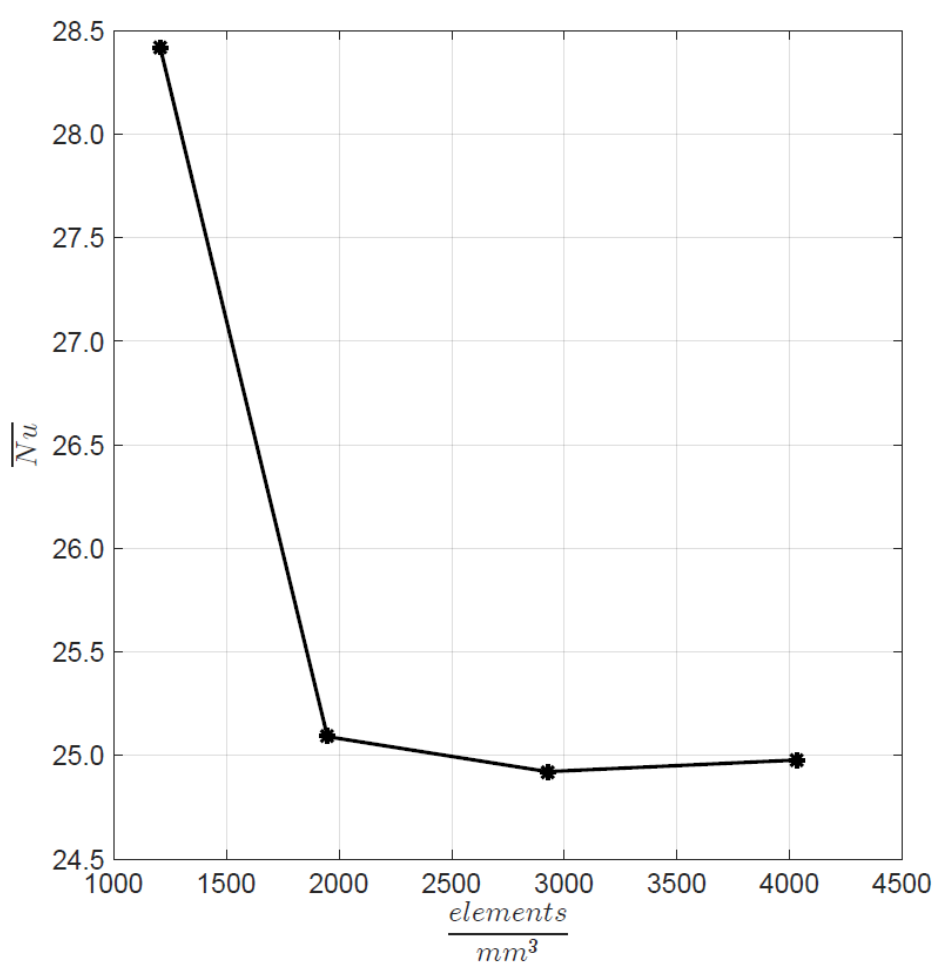

Figure 4. The results of the study of mesh independency. 


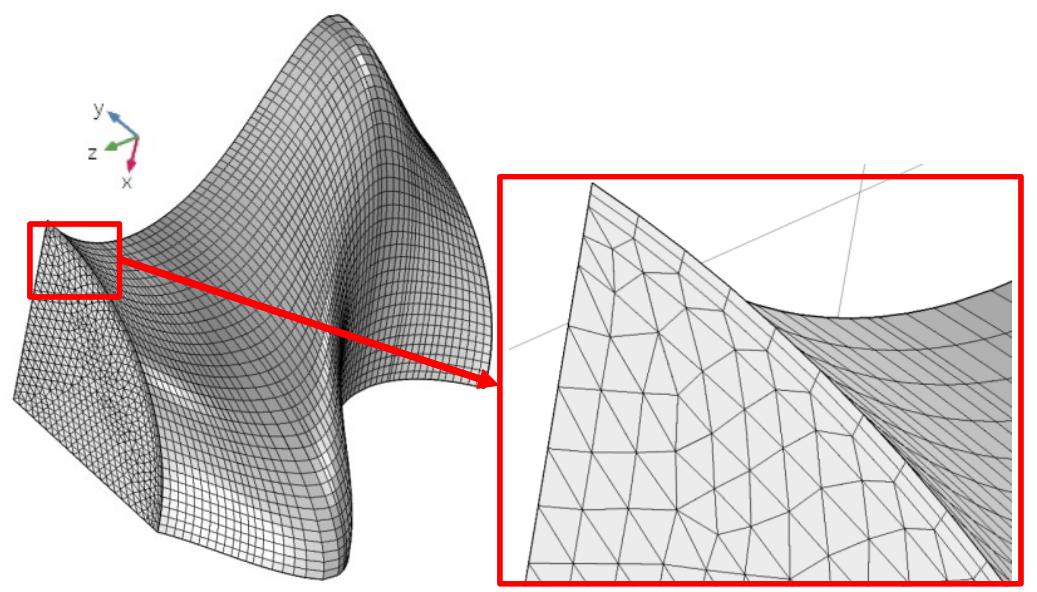

Figure 5. The isometric view of the modelled geometry of a double corrugated tube after being meshed in COMSOL. The boundary layers are shown in the zoomed in view.

Finally, the inaccuracy of the mass and energy balances for each model was less than $0.16 \%$ showing that all the models were adequately accurate. Note that the mass and energy balances were calculated for each modelled tube and only the largest value is reported.

\subsection{Governing equations and boundary conditions}

The governing equations were formulated in Cartesian coordinates. The SIMPLE algorithm was used to couple steady-state equations for non-isothermal flow of incompressible fluid with constant properties. Laminar, pressure driven, fully developed internal flow was modelled. Thus, the continuity equation is formulated as given by Eq. 7.

$$
\nabla \cdot \boldsymbol{u}=0
$$

where $\boldsymbol{u}$ is the fluid velocity vector.

The momentum conservation equation is given by Eq. 8 .

$$
-\rho(\boldsymbol{u} \cdot \nabla \boldsymbol{u})=\nabla p-\mu \nabla^{2} \boldsymbol{u}
$$

Here $p$ is the pressure field. The heat transport equation, neglecting pressure work and viscous dissipation, is given by Eq. 9 .

$$
\rho c_{p} u \nabla T=\nabla \cdot(k \nabla T)
$$

To ensure that the flow is fully developed, a periodic boundary condition was applied in the form of a pressure gradient. No-slip boundary conditions were applied on the solid wall. A solid wall is treated as a streamline by imposing no-slip BC as can be seen from Eq. 10.

$$
\boldsymbol{u} \cdot \boldsymbol{n}=\boldsymbol{U} \cdot \boldsymbol{n}
$$

Where $U$ is the velocity vector of the solid body and $n$ is the unit normal to the surface of the solid body. All the geometries were modelled for the same pressure drop.

The governing equations were solved using the finite element method in Comsol. P2+P1 fluid discretization was used, which provides quadratic interpolation of the velocity field and linear interpolation of the pressure field. The stationary PARDISO solver with relative tolerance of $10^{-6}$ was used for all the modelled geometries.

\subsection{Method of analysis}

The main outputs of the thermal model are the fluid flow rate for the specified pressure drop and the resulting temperature profile. The thermal performance and hydraulic characteristics of the analysed double corrugated tubes were evaluated using average Nusselt number $\overline{N u}$, the number of transfer units $(N T U)$ method, and comparing the volumetric flow rate $(\dot{V})$ and performance evaluation criteria (PEC).

Eq. 11 defines the net rate of outflow of thermal energy, $q$, for an incompressible fluid. 


$$
q=\dot{m} c_{p}\left(T_{i}-T_{o}\right)
$$

Where $T$ is the bulk temperature at the inlet $i$ and outlet $o$ of a modelled tube, respectively. Then the average convective heat transfer coefficient, $\bar{h}$, is calculated using Eq. 12.

$$
\bar{h}=\frac{q}{A_{s} \Delta T_{l m}}
$$
Eq. 13.

Where $A_{s}$ is a surface area and $\Delta T_{l m}$ is the log mean temperature difference, which is defined by

$$
\Delta T_{l m}=\frac{\Delta T_{o}-\Delta T_{i}}{\ln \left(\frac{\Delta T_{o}}{\Delta T_{i}}\right)}
$$

Where $\Delta T_{o, i}$ is temperature difference between temperature of a tube wall, $T_{\mathrm{s}}$, and the bulk temperature, $T$. Then average Nusselt number, $\overline{N u}$, is calculated using Eq. 14.

$$
\overline{N u}=\frac{\bar{h} D_{h}}{k}
$$

Where $D_{\mathrm{h}}$ is hydraulic diameter and $k$ is thermal conductivity of water.

The friction factor $f$ is calculated from Eq. 15 using the simulation results for mean velocity, $u_{\mathrm{m}}$, and specified pressure drop, $\Delta p$.

$$
f=\frac{2 \Delta \mathrm{p} D_{h}}{\rho \mathrm{u}_{\mathrm{m}}^{2} l}
$$

Where $l$ is the tube length. The global performance of the double corrugated tubes was analysed using the most commonly adopted performance evaluation criterion $P E C$, which is defined by Eq. 16 $[1,13]$.

$$
P E C=\frac{\overline{N u} / \overline{N u_{0}}}{\left(f^{f} / f_{0}\right)^{1 / 3}}
$$

Where $f_{0}$ is the Darcy-Weisbach friction factor for a straight tube given in Eq. 17 and $\overline{N u_{0}}$ is the Nusselt number of a straight tube based on simulation results and calculated using Eq. 11-14.

$$
f_{0}=\frac{64}{R e}
$$

$N T U$ is calculated as defined by Eq. 19.

$$
N T U=-\ln (1-\varepsilon)
$$

Where $\varepsilon$, is efficiency of a heat exchanger defined by Eq. 20 .

$$
\varepsilon=\frac{q}{q_{\max }}
$$

Where $q_{\max }$ is maximum possible heat transfer that is calculated using Eq. 21 .

$$
q_{\max }=\dot{m} c_{p}\left(T_{i}-T_{s}\right)
$$

\section{Results and discussion}

As it was discussed above, the purpose of enhanced geometries is to disturb thermal boundary layers and enhance the heat transfer. The wall of a double corrugated tube periodically impinges a flow and thus, prevents thermal development of the flow. A detail explanation of the changes in flow and temperature profiles is given for a double corrugated tube with an ellipse base and $D_{\mathrm{h}}$ constant. The geometrical characteristics of the presented tube are $A R=1.6$ and $p=7.5 \mathrm{~mm}$. The analysis is presented in comparison with a corresponding straight tube. By holding the pressure drop across the tubes constant, 
the corrugated tubes reduce flow rate, but the tubes could be directly substituted for straight tubes without requiring a different pump or pipes/fittings. Figure 6 presents the comparison of a heat flux through the wall of a double corrugated tube (a) and a straight tube (b). One can see that a high heat transfer rate takes place over the entire length of the double corrugated tube because the thermal boundary layers are interrupted by the tube geometry, while the straight tube exhibits high heat transfer rates at the tube inlet that gradually diminish in the flow direction. It can be seen that the highest heat transfer rates occur in the regions where one of the axis of ellipses are smallest. Note that the flow rate in the straight tube is twice that of the double corrugated tube under the same pressure drop.
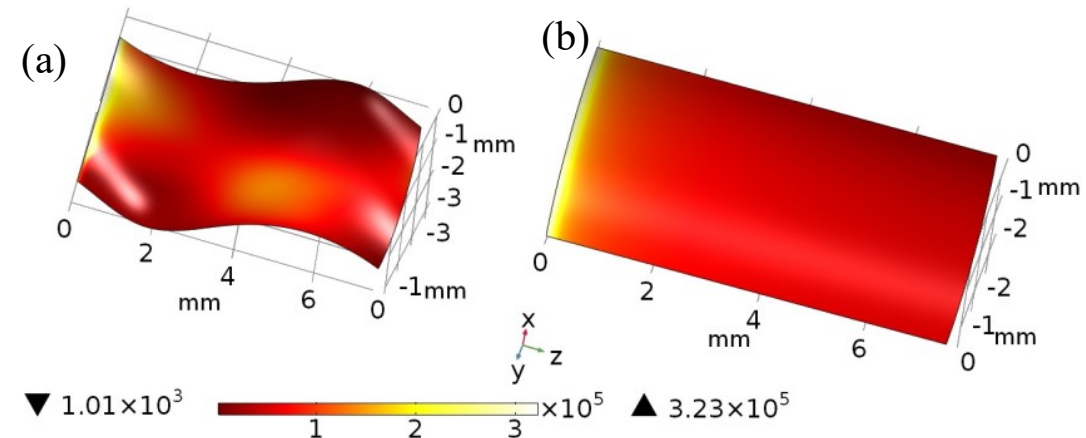

Figure 6. The heat flux in a double corrugated (flow rate $0.002 \mathrm{~m}^{3} \mathrm{~h}^{-1}$ ) (a) tube and a straight (flow rate $0.004 \mathrm{~m}^{3} \mathrm{~h}^{-1}$ ) (b) tube at the same pressure drop $\Delta p=1.843 \mathrm{~Pa}$. The ellipse-based double corrugated tube has following geometrical characteristics: $A R=1.6, p=7.5 \mathrm{~mm}$.

Figure 7 shows the flow velocity and the temperature field of the straight and a corrugated tubewith $A R=1.6$ and $p=7.5 \mathrm{~mm}$. As expected, the velocity field does not change along the flow direction in the straight tube at laminar fully hydraulically developed conditions. Moreover, one can see from Figure 7 (a) that the temperature boundary layers develop rather quickly along the flow direction. On the other hand, the flow is contorted in the radial axis and the walls of the double corrugated tubes have a periodic contact to the faster moving fluid along the tube on both $x$ and $y$ axis in the double corrugated tubes, as it is seen in Figure 7 (b). In this way, warmer fluid is periodically pushed closer to the tube wall and thus thermal gradients in the radial direction are increased as shown in Figure 8. 

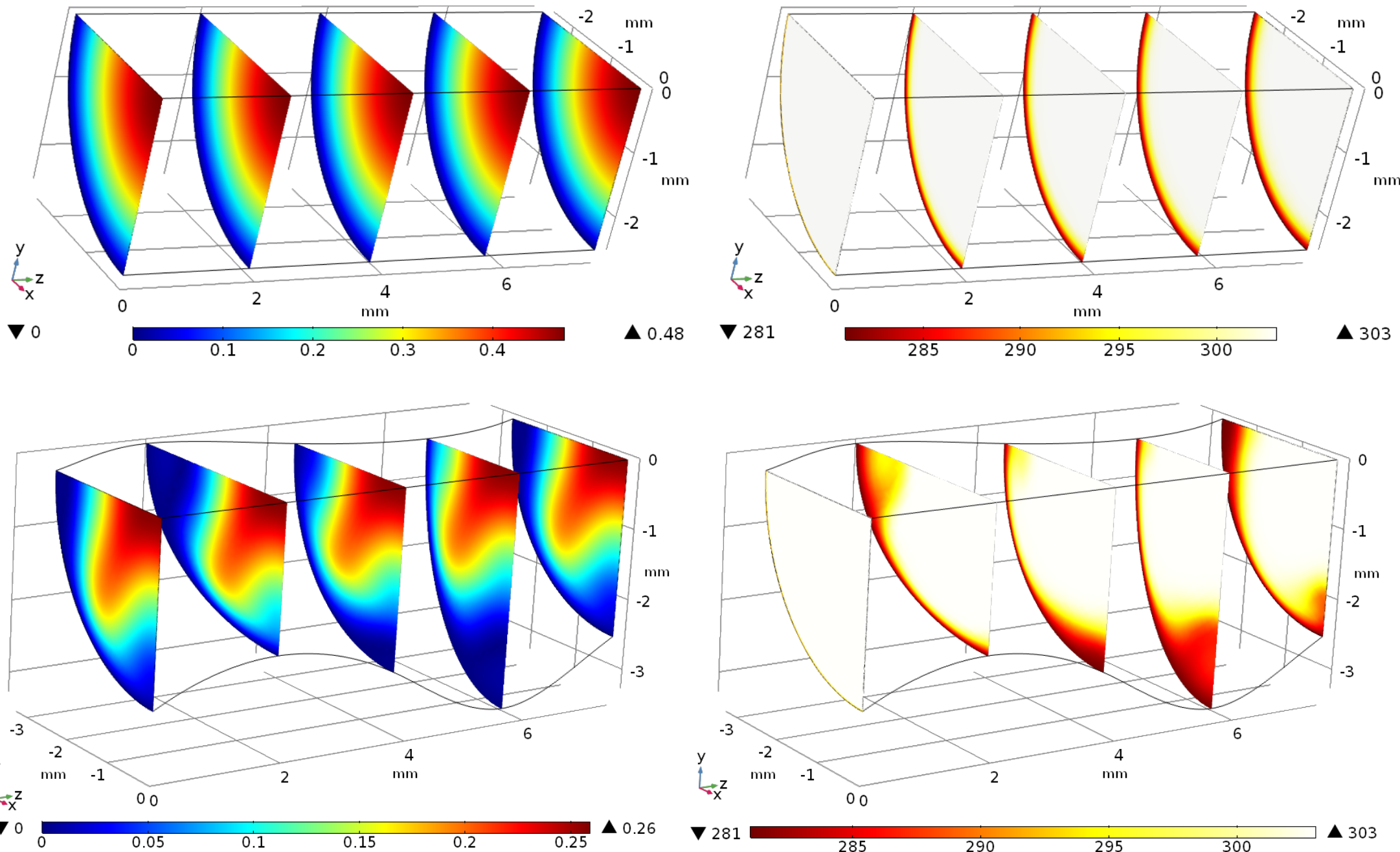

Figure 7. Three-dimensional temperature (left side, scale bar in $\mathrm{K}$ ) and velocity (right side, scale bar in $\mathrm{m} / \mathrm{s}$ ) fields at $\Delta p / l=246 \mathrm{~Pa} / \mathrm{m}$. (a) a straight tube, $l=7.5 \mathrm{~mm}$. (b) the double corrugated tube with $A R=1.6, p=7.5 \mathrm{~mm}, l=7.5 \mathrm{~mm}$. 
Figure 8 shows the normalized temperature profiles at the outlet of the above presented double corrugated and straight tubes under cooling conditions. One can see that the temperature gradient in the radial axis of the double corrugated tube is greater than in the straight tube. This indicates that there is a larger portion of the fluid that takes part in the heat transfer process in the double corrugated geometry compared to the straight tube.

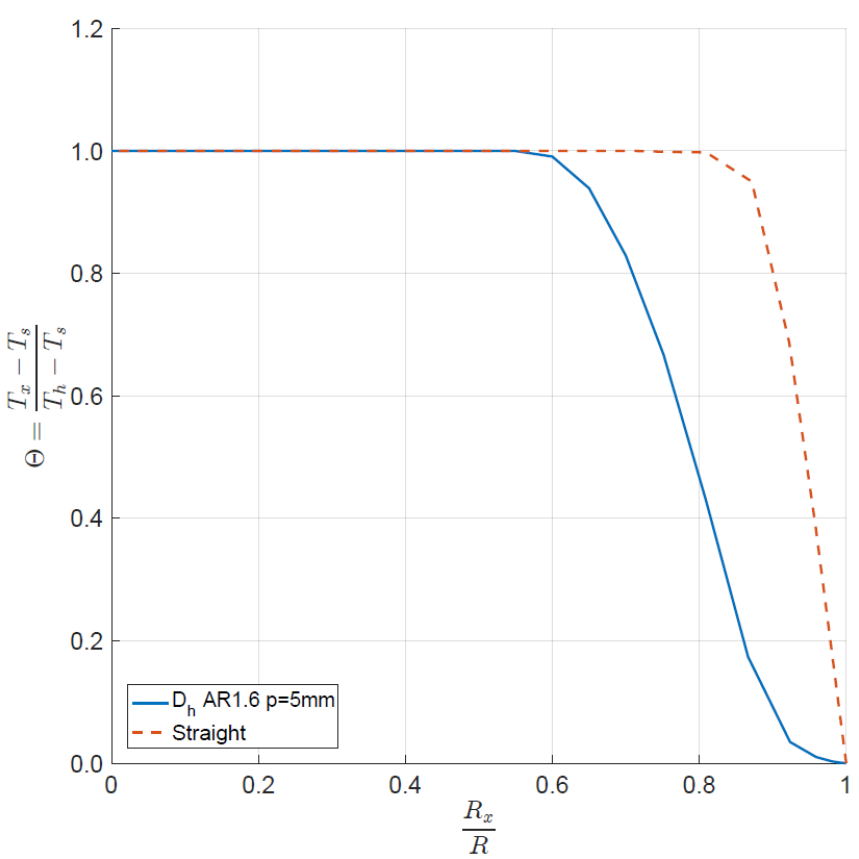

Figure 8. The flow temperature profile in the double corrugated tube, presented in Figure 6, and straight tube at the outlet of geometries.

Further comparison of the changes of a flow in a double corrugated and a straight tube showed that the velocity profile in an annular face is also tweaked. Figure 9 shows the corrugation effect on the velocity profile in an ellipse-based double corrugated tube and a straight tube of the same length at $[0 ; 1 / 4 ; 1 / 2 ; 3 / 4 ; 1]$ of a period. The geometry of a double corrugated tube interrupts the flow profile significantly and especially close to the tube walls. This signifies that the boundary layers are strongly disturbed, which increases heat transfer and pressure drop.

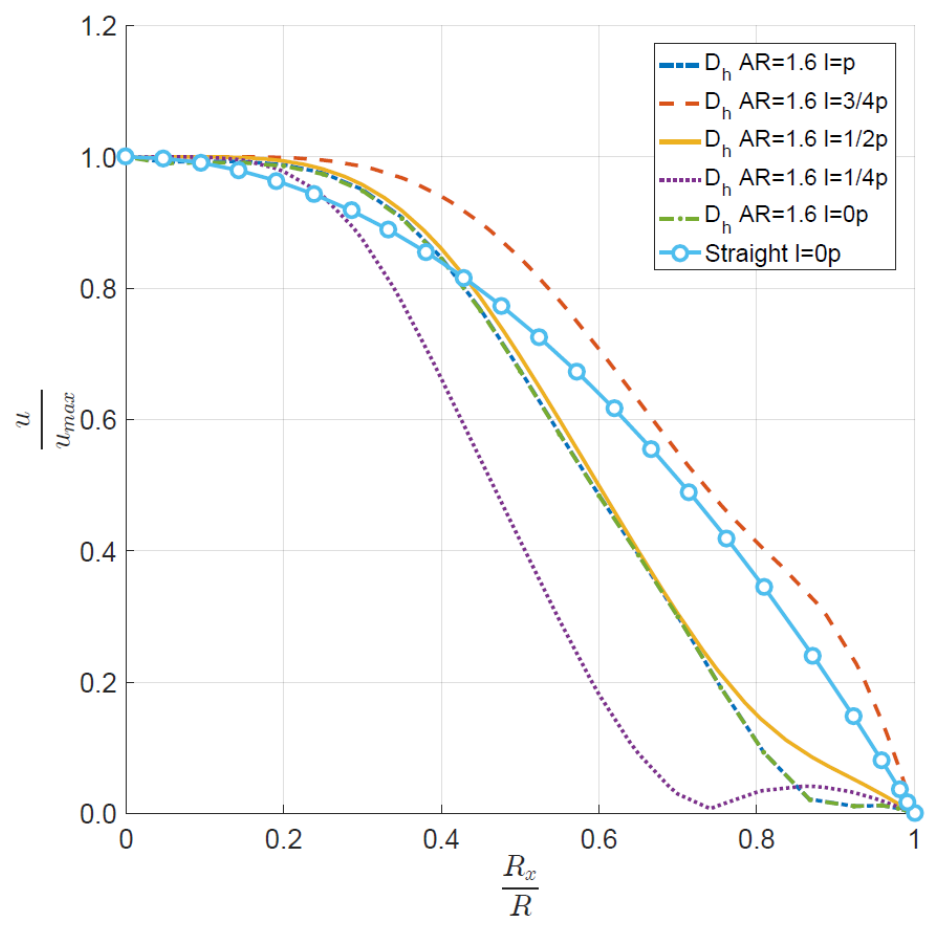


By analysing the Figure 9, one can raise a question how then the mean velocity in an annular face $\bar{u}$ is changing along the double corrugated tubes. Based on fundamental knowledge of the fluid dynamics, one can expect the mean flow velocity remain constant in tube with $A_{\mathrm{c}}$ held constant since the mass conservation law must be satisfied. On the other hand, the concept of $D_{\mathrm{h}}$ yields that due to maintained effective opening of a flow channel, the conservation of momentum must be maintained. Therefore, $\bar{u}$ should vary along the tubes with $D_{\mathrm{h}}$ held constant. This can be seen in Figure 10 , where the normalized $\bar{u}$ in an annular face is shown along ellipse-based double corrugated tubes. One can see that the double corrugation approach with $D_{\mathrm{h}}$ held constant significantly induces throttling of the mean flow velocity along the tube. It is also clear that the $A R$ has bigger impact on the throttling effect than $p$. The fluctuation of $\bar{u}$ in a double corrugated tube with $A_{\mathrm{c}}$ constant occurred due to geometrical inaccuracies reported in section 2 .

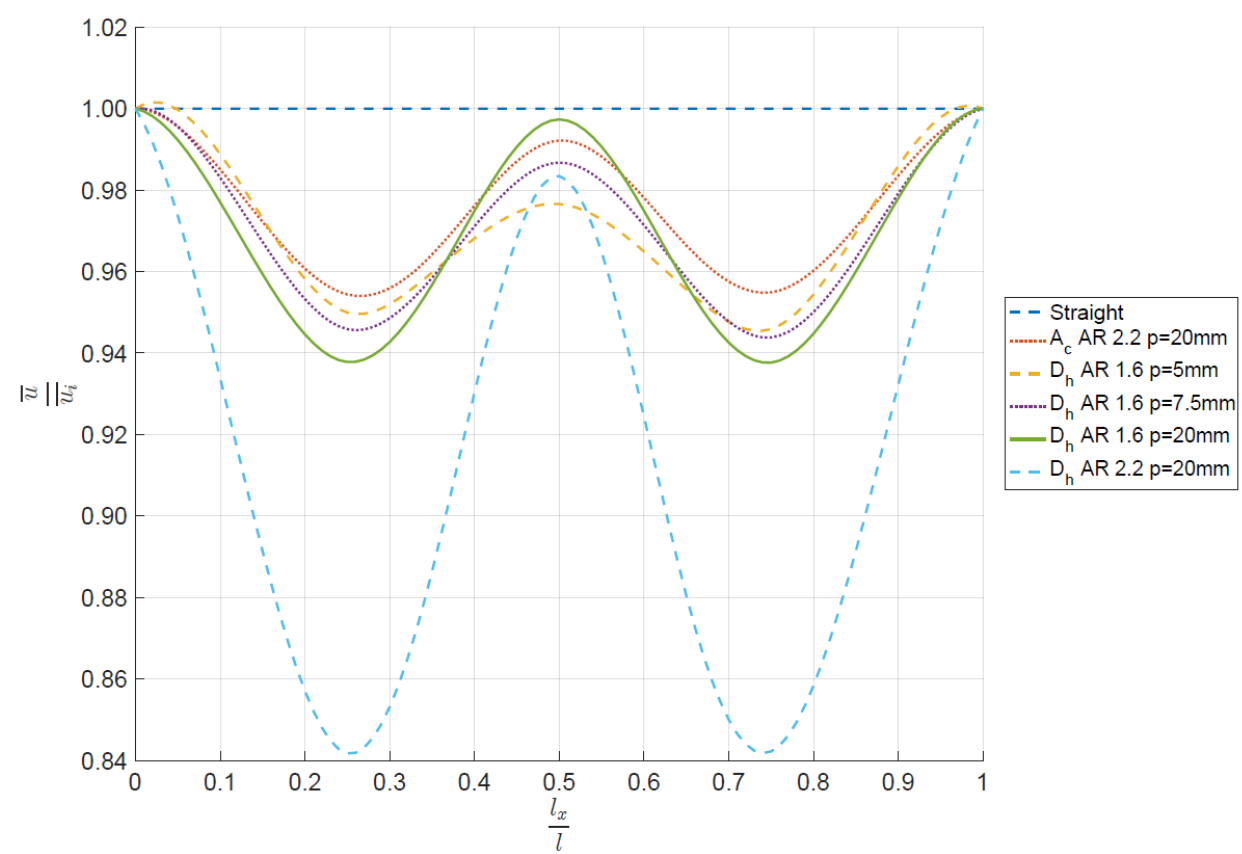

Figure 10. Normalized annular flow velocity $\bar{u}$ as a function of relative tube length in the ellipse-based double corrugated tubes and a straight tube.

The double corrugation not only tweaks the flow, but also enhances the surface area of the tubes. Figure 11 shows how much the inner surface area $A_{\mathrm{s}}$ of the double corrugated tubes increases compared to a straight tube. Since $A_{\mathrm{s}}$ for $p \geq 50 \mathrm{~mm}$ approaches the value of a straight tube and the ratio of the surface area follows an asymptotic behaviour, the tubes with $p \geq 50 \mathrm{~mm}$ are not presented in this figure to avoid clutter. One can see that the tubes with constant $D_{\mathrm{h}}$, regardless of their base geometry, generally have higher increase in $A_{\mathrm{s}}$ than the tubes with the constant $A_{\mathrm{c}}$. The inner surface area increases with increasing $A R$ and with decreasing $p$. The biggest increase in the inner surface area $A_{\mathrm{s}}$ is for tubes with $A R=2.2$ at $p=5 \mathrm{~mm}$ and it is up to $34 \%, 26 \%, 25 \%$ for the tubes with the constant $D_{\mathrm{h}}$ of both types, and constant $A_{\mathrm{c}}$ for ellipse-based and super ellipse-based, respectively. In the next figures, only selected modelling results will be presented due to space limitations. 

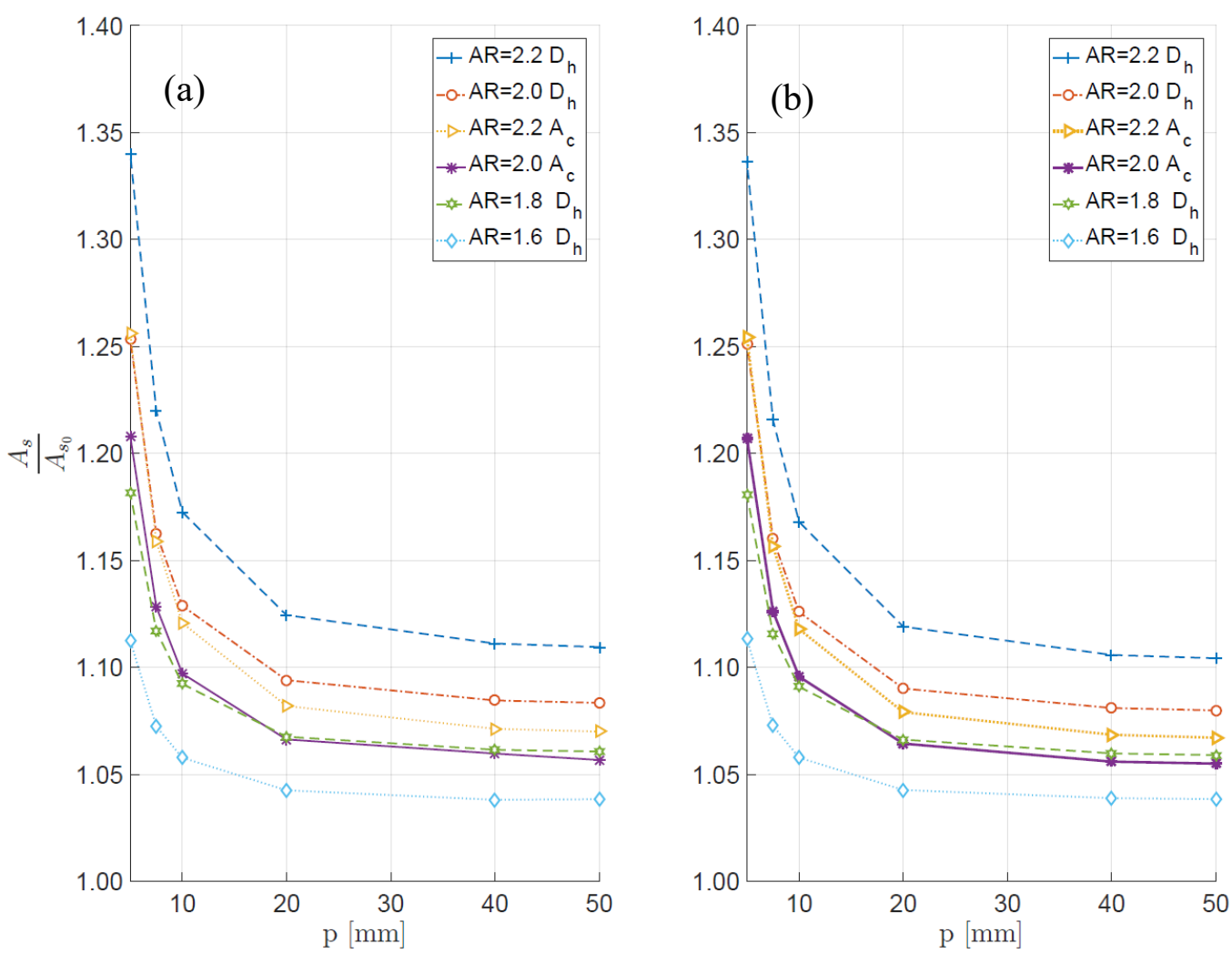

Figure 11. Increase in the inner surface area of double corrugated tubes with respect to a corresponding straight tube. The plots show double corrugated tubes with an ellipse-based holding (a) a super ellipse-base holding (b).

Figure 12 shows that $\overline{N u}$ increases in double corrugated tubes even though $\Delta p$ is maintained constant rather than $R e$. One can see that $\overline{N u}$ increases up to $20 \%$ in double corrugated tubes compared to a straight tube. The double corrugated tubes with the greater $A R$ show higher increase in $\overline{N u}$. It is noticeable that for both ellipse-based and super ellipse-based tubes the $\overline{N u}$ increases in the same manner. 8 In addition, once the $p$ exceeds value of $10 \mathrm{~mm}$, double corrugated tubes with constant $D_{\mathrm{h}}$ show slightly 9 higher values in $\overline{N u}$ than tubes with constant $A_{\mathrm{c}}$. However, $N T U$ analysis suggest that double corrugated tubes with $A_{\mathrm{c}}$ held constant are more efficient than tubes with constant $D_{\mathrm{h}}$ (Figure 13). 


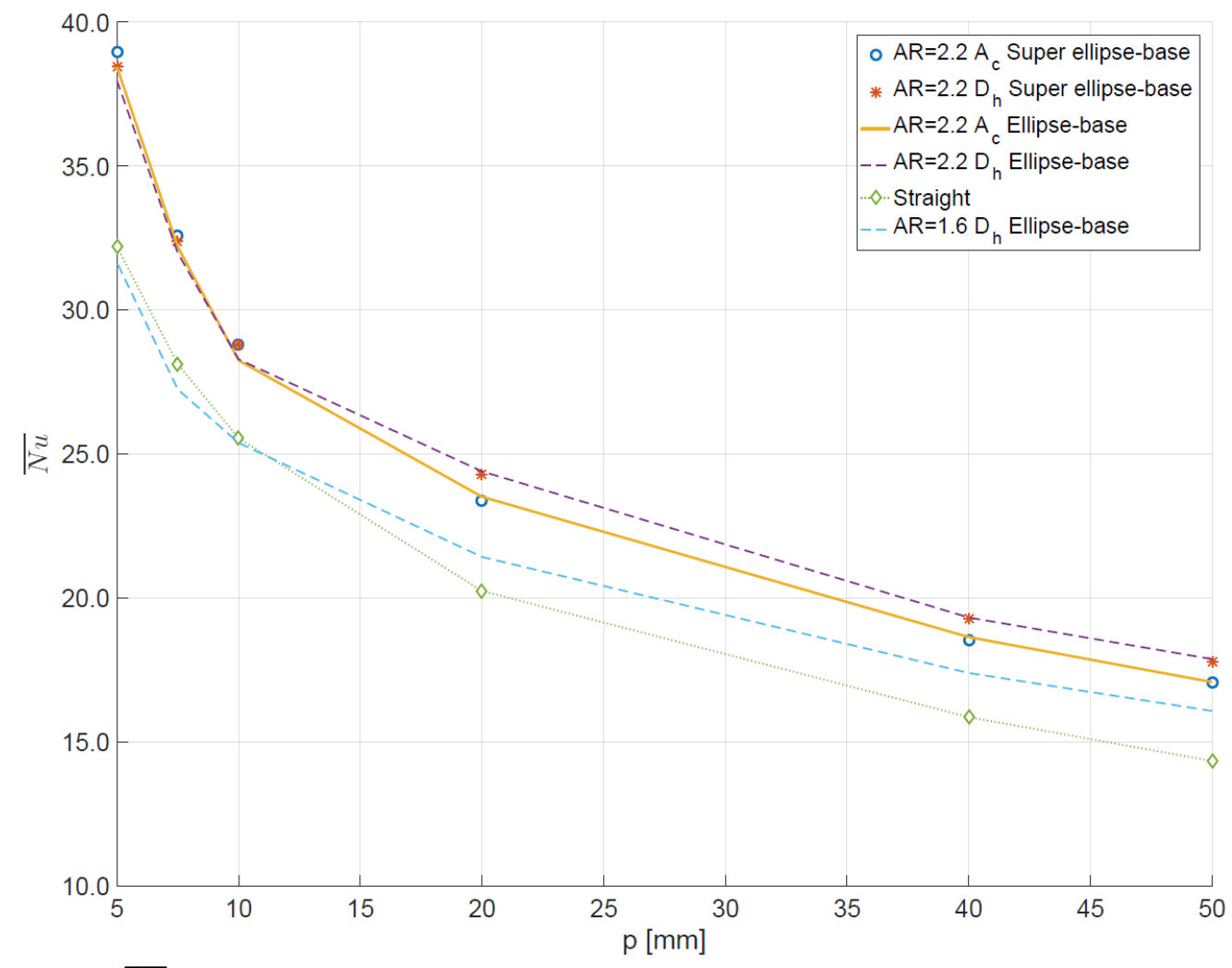

Figure 12. The $\overline{N u}$ in ellipse-based and in super ellipse-based double corrugated tubes as a function of the period at constant $\Delta p$.

Figure 13 shows the NTU ratio in double corrugated tubes with respect to corresponding straight tubes. One can see that the $N T U$ ratio decreases significantly with decreasing either $A R$ or $p$. The double corrugated tubes with $A_{\mathrm{c}}$ constant at the most intense corrugation show more than $400 \%$ increase in $N T U$ ratio for both ellipse-base and super-ellipse base cases. The $N T U$ ratio for tubes with the $D_{\mathrm{h}}$ constant exceeds $330 \%$ for both ellipse-base and super-ellipse base cases. The $N T U$ drops drastically as the period increases above $10 \mathrm{~mm}$ and eventually approaches values of straight tubes at high values of $p$. It should be noted that since the pressure drop is held constant, the flow rate is lower for the corrugated tubes than the straight tube (Figure 14). Since the double corrugated tubes with ellipse-base and super ellipse-base shows similar NTU behaviour, however somewhat lower flow resistance is observed for the previous case, several cases of ellipse-based double corrugated tubes were selected for the study varying $R e$. 

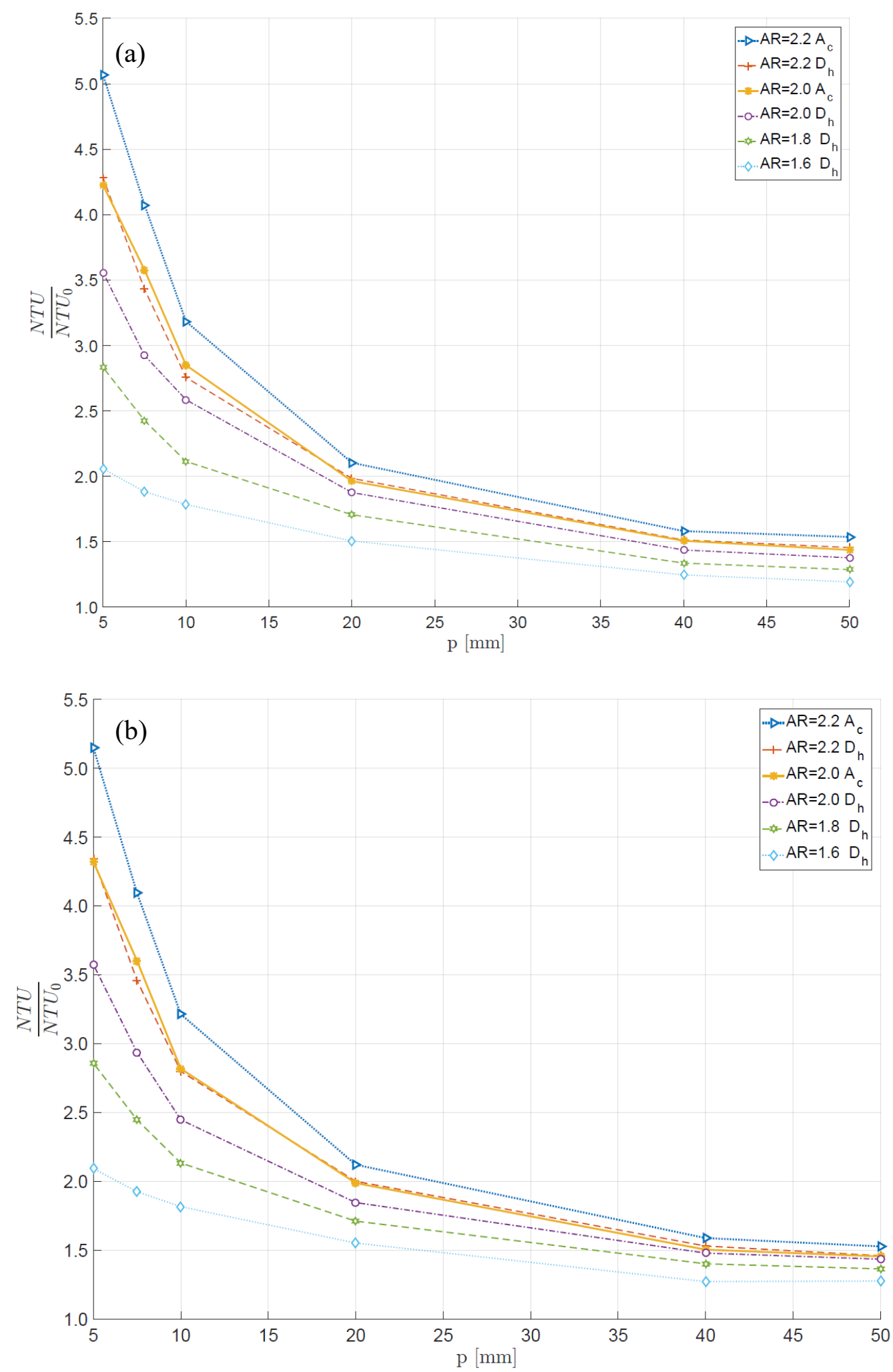

Figure 13. Ratio of NTU in ellipse-based (a) and in super ellipse-based (b) double corrugated tubes as a function of the period at constant $\Delta p$.

Figure 14 shows the ratio of the flow rates in the double corrugated tubes and corresponding straight tubes for the same pressure drop. One can see that the flow resistance is lower in the double corrugated tubes with the $D_{\mathrm{h}}$ held constant rather than $A_{\mathrm{c}}$ held constant. The volumetric flow rate ratio is 3.6 and 4.2 times lower in double corrugated tubes with constant $D_{\mathrm{h}}$ and constant $A_{\mathrm{c}}$, respectively, than in a straight tube. The double corrugated tubes with an ellipse-base showed $5 \%$ lower flow resistance than the tubes with a super ellipse-base. The very sharp decrease of $\dot{V}$ in the region of intense corrugation indicates a significant flow resistance that compromises overall performance (Figure 15). The simulation results show that flow at the high $R e$ is insensitive to a high corrugation with a short $p$. In other words, flow at high Re passes the intense corrugation as if only a diameter of a tube would be 
reduced. Thus, it is more efficient to use corrugated tubes with longer corrugation period for a flow at high $\operatorname{Re}[26,32]$.
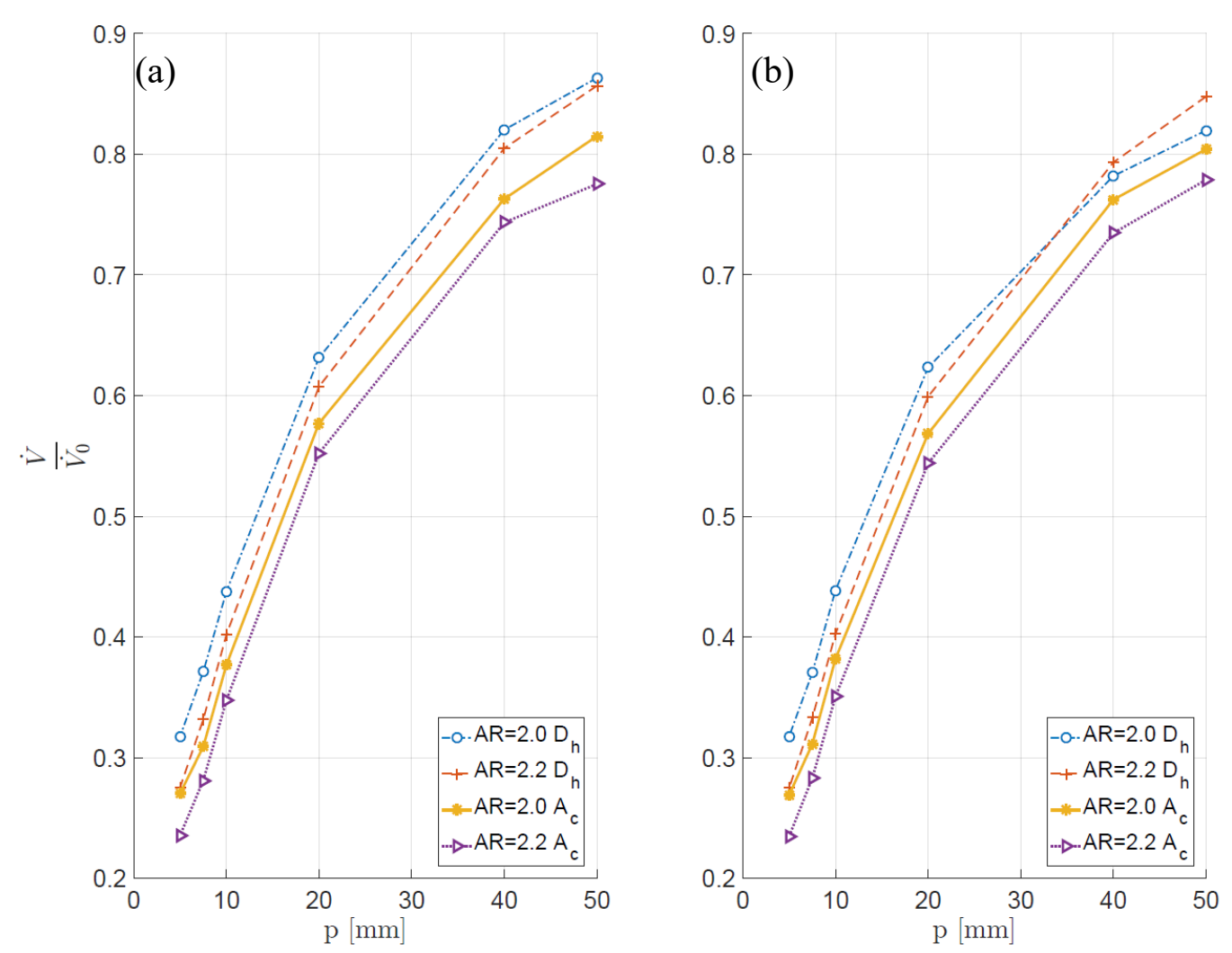

Figure 14. The ratio of the volumetric flow rate $\dot{V}$ in ellipse-based (a) and super ellipse based (b) double corrugated tubes as a function of the period of the tubes at the constant $\Delta p$.

The PEC analysis showed that ellipse-based double corrugated tubes achieve $14 \%$ higher efficiency than straight tubes, while supper ellipse-based double corrugated tubes demonstrate $11 \%$ better performance than straight tubes when $p \leq 50 \mathrm{~mm}$ (Figure 15). From Figure 15 (a), one can noticed that ellipse-based double corrugated tubes with $A_{\mathrm{c}}$ constant show global performance equivalent to a straight tube $(P E C=1)$ once $p=50 \mathrm{~mm}$. This means that the same the same or even higher efficiency provided by double corrugated tubes is obtained using geometry that is more compact. Moreover, up to $10 \%$ higher $P E C$ is achieved in ellipse-based double corrugated tubes at lower Re (Figure 16). From Figure 16, one can see that at lower Re, the $P E C$ is less dependent on $A R$ than on $p$. It is noticeable that double corrugated tubes with shorter $p$ are more efficient at lower Re. However, the overall performance decreases significantly when the corrugation period exceed a certain value. At that point, the thermal performance of the double corrugated tubes approaches a straight tube, while the flow rate is still significantly lower.

Performance of the double corrugated tubes was compared to the AEA tubes reported by Khaboshan and Nazif, [13]. The latter tubes were modelled in the turbulent flow regime with constant temperature of the tube wall. The AEA tubes showed up to $10 \%$ higher efficiency than an equivalent straight tube in terms of $P E C$ with at lower Re. The double corrugated tubes presented in this study demonstrate somewhat higher efficiency than AEA tubes, which is mostly due to the smoother geometrical transitions that reduce pressure losses in the former tubes. 

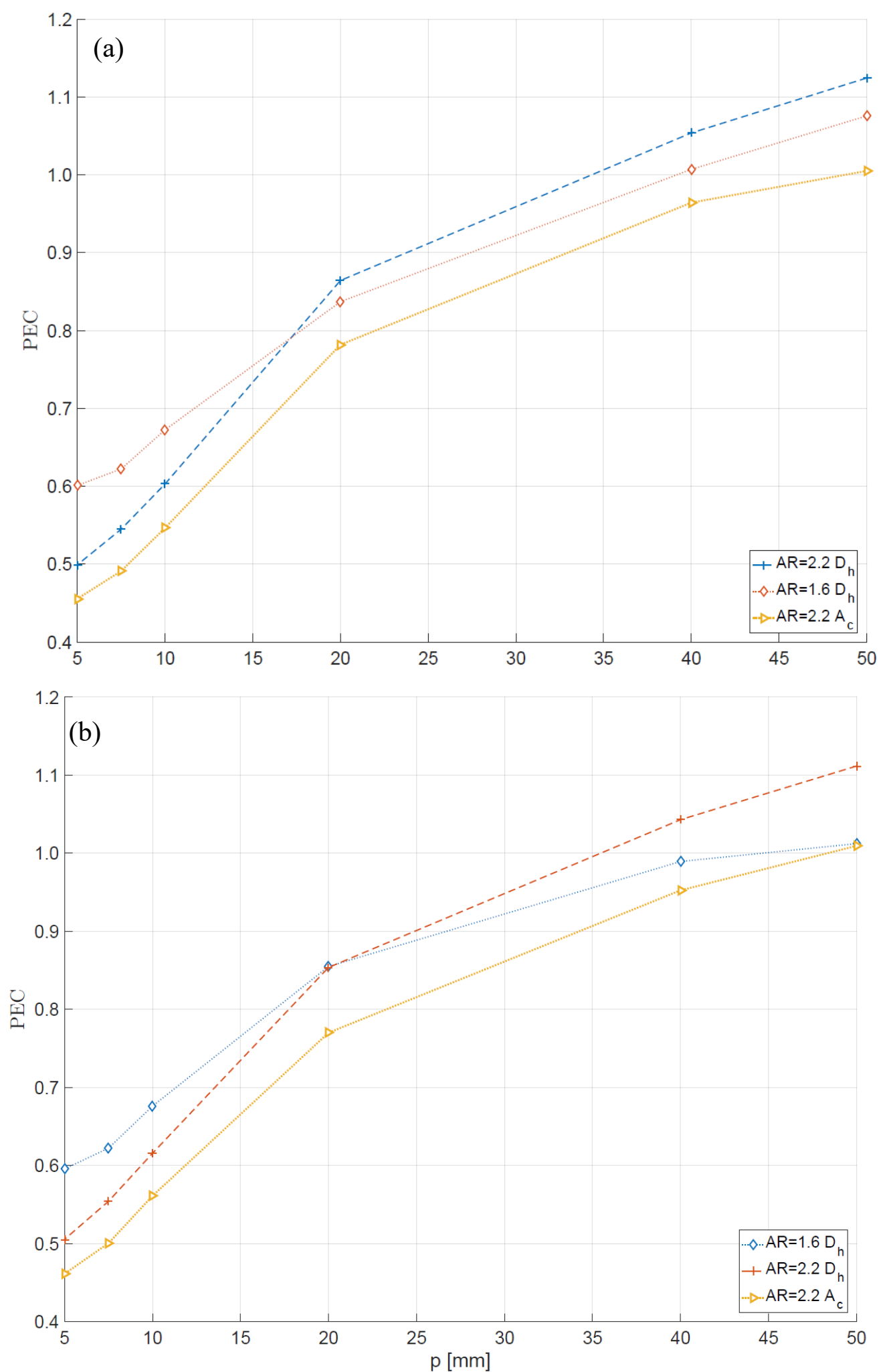

Figure 15. The $P E C$ of ellipse-based (a) and super ellipse-based (b) double corrugated tubes as a function of a period at the constant $\Delta p$. 


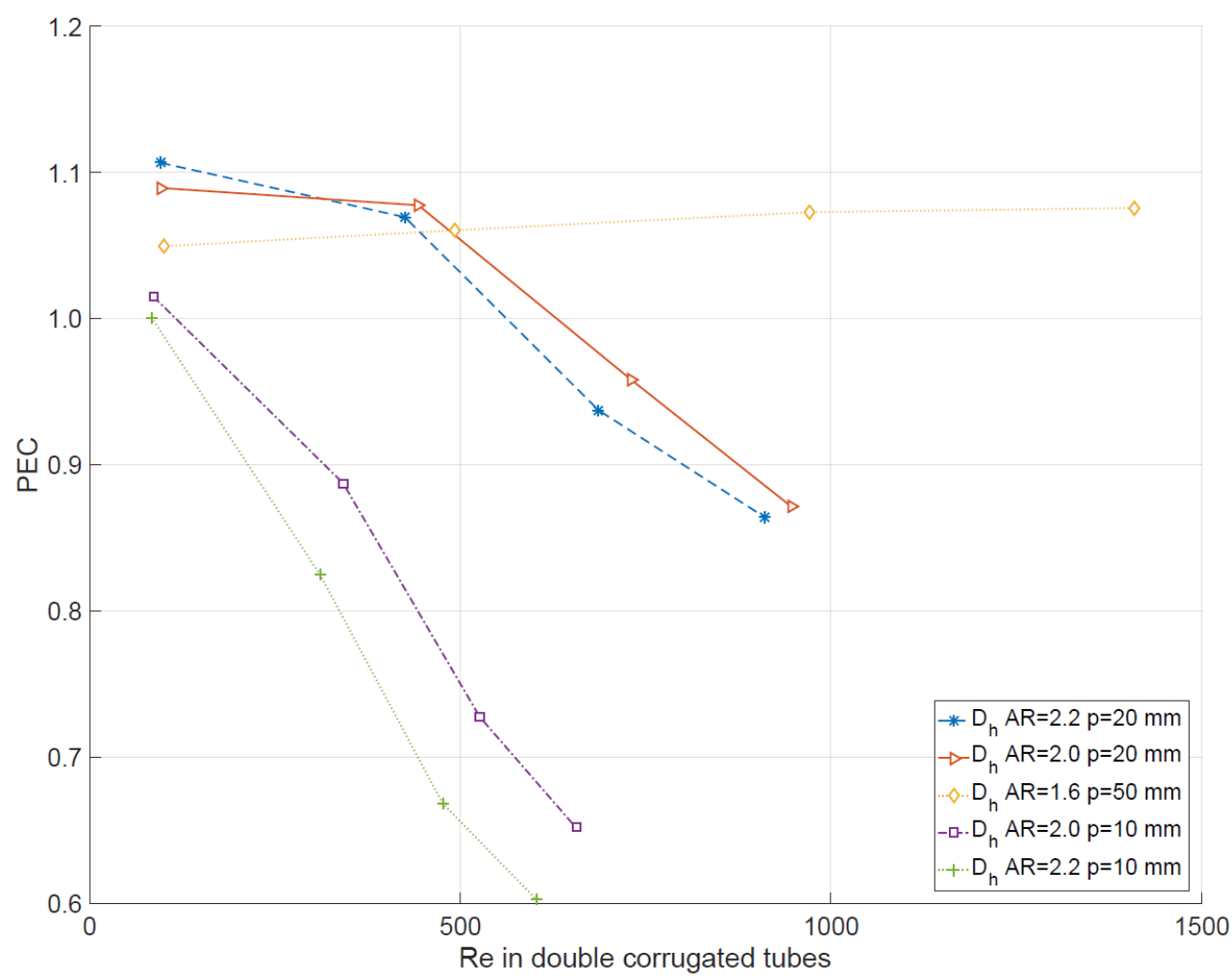

Figure 16. The $P E C$ in ellipse-based tubes as a function of $R e$.

Finally, the analysis of the thermo-hydraulic performance of the presented double corrugated tubes was performed using same approach as for the straight tube including the numerical model. The simulation results show that the double corrugated geometry has potential to enhance the heat transfer with acceptable penalty in pressure drop. However, experimental investigation is necessary in order to understand the thermo-hydraulic behaviour and find out a real potential of the presented double corrugated tubes.

\section{CONCLUSIONS}

In this paper, a numerical comparison of heat transfer performance of double corrugated tubes and straight tubes for laminar flow conditions was presented. Constant pressure drop and wall temperature conditions were analysed. Two types of double corrugated tubes with constant hydraulic diameter and constant cross-section area were analysed for tubes with either ellipse-based or super ellipse-based crosssections. The efficiency and global thermo-hydraulic performance of the tubes were characterized in terms of the number of transfer units $(N T U)$, average Nusselt number $(\overline{N u})$ and performance evaluation criterion $(P E C)$, which evaluates performance at the same pumping power.

The simulation results showed that the novel geometry of double corrugated tubes affects the fluid flow by disturbing thermal boundary layers and modifying the flow profile compared to a straight tube as well as by increasing the surface area of the inner surface of the tube. These result in enhanced heat transfer and a reduced fluid flow rate for a constant pressure drop. $N u$ increases up to $20 \%$ for intensively corrugated tubes with ellipse and super ellipse-based cross sections. However, the flow rate reduction in super ellipse-based double corrugated tubes is $5 \%$ higher than in ellipse-based tubes. The double corrugated tubes with constant $D_{\mathrm{h}}$ show lower flow rate reduction than tubes with constant $A_{\mathrm{c}}$, when comparing the ratio of volumetric flow rate with a straight tube. It is 3.6 and 4.2 times lower in double corrugated tubes with constant $D_{\mathrm{h}}$ and constant $A_{\mathrm{c}}$, respectively.

The thermal performance in terms of $N T U$ for double corrugated tubes with $A_{\mathrm{c}}$ constant is more than $400 \%$ greater when compared to a straight tube. The double corrugated tubes with constant $D_{\mathrm{h}}$ showed lower $N T U$ than tubes with constant $A_{c}$. However, it is still more than $330 \%$ greater than for a straight tube. It was also shown that the $N T U$ ratio for double corrugated tubes with a super ellipse-based cross-section is slightly higher than for tubes with an ellipse-based cross-section. 
Numerical results show that the ellipse-based tubes with constant hydraulic diameter are more than $14 \%$ more effective than equivalent straight tubes when the pressure drop per length of tube is held constant. Even though the super ellipse-based tubes show slightly higher thermal performance than ellipse-based tubes, they show lower $P E C$ values due to a somewhat higher flow rate reduction. The study results of varying $R e$ revealed that the double corrugated tubes are $10 \%$ more efficient than corresponding straight tubes at lower $R e$. It was also concluded that corrugations with shorter periods are more efficient at lower $R e$. Moreover, an ellipse-based double corrugated tube with $A R=2.2$ and constant $A_{\mathrm{c}}$ showed $P E \mathrm{C}$ values equivalent to a straight tube for $p=50 \mathrm{~mm}$. It is worth mentioning that in this case the double corrugated tubes are as efficient as a straight tube while being more compact.

Moreover, the study shows that fluid at high $R e$ passes peaks in corrugation, when the corrugation period is short, with a minor disturbance in the flow path. For these reasons, mentioned above, the recommendation is to use double corrugated tubes with the short corrugation periods at lower $R e$, and tubes with the longer periods in applications where faster flow is required.

Additionally, ellipse-based tubes have an additional advantage of having a circular inlet and outlet. This feature enables fast and easy mounting to a new or existing application without any additional modifications. Moreover, the double corrugated tube geometry allows for stacking of tube bundles, further increasing compactness of a heat exchanger. However, one should select accurately the type of the double corrugated tubes to meet requirements of a specific application the best.

\section{ACKNOWLEDGMENTS}

Luca Cattani would like to express his gratitude to the Emilia-Romagna Region (POR-FESR 20142020): "Applicazione delle micro/nanotecnologie per lo sviluppo di componenti innovativi per gli impianti di condizionamento" - NANOFANCOIL).

\section{REFERENCES}

[1] R.L. Webb, N.-H. Kim, Principles of enhanced heat transfer, 2nd ed., Taylor \& Francis, Abingdon, Great Britain, 2005.

[2] S. Rainieri, G. Pagliarini, Convective heat transfer to orange juice in smooth and corrugated tubes, Int. J. Heat Technol. 15 (1997) 69-75.

[3] J. Hærvig, K. Sørensen, T.J. Condra, On the fully-developed heat transfer enhancing flow field in sinusoidally, spirally corrugated tubes using computational fluid dynamics, Int. J. Heat Mass Transf. 106 (2017) 1051-1062.

[4] A. Harleß, E. Franz, M. Breuer, Heat transfer and friction characteristics of fully developed gas flow in cross-corrugated tubes, Int. J. Heat Mass Transf. 107 (2017) 1076-1084.

[5] J.F. Fan, W.K. Ding, J.F. Zhang, Y.L. He, W.Q. Tao, A performance evaluation plot of enhanced heat transfer techniques oriented for energy-saving, Int. J. Heat Mass Transf. 52 (2009) 33-44.

[6] M.W. Rohsenow, P.J. Hartnett, I.Y. Cho, Handbook of heat transfer calculations, 3rd ed., 1998.

[7] A. Barba, S. Rainieri, M. Spiga, Heat transfer enhancement in a corrugated tube, Int. Commun. Heat Mass Transf. 29 (2002) 313-322.

[8] Z.S. Kareem, S. Abdullah, T.M. Lazim, M.N. Mohd Jaafar, A.F. Abdul Wahid, Heat transfer enhancement in three-start spirally corrugated tube: Experimental and numerical study, Chem. Eng. Sci. 134 (2015) 746-757.

[9] S. Rainieri, F. Bozzoli, L. Cattani, Passive techniques for the enhancement of convective heat transfer in single phase duct flow, J. Phys. Conf. Ser. 547 (2014) 0-10.

[10] Y. Dong, L. Huixiong, C. Tingkuan, Pressure drop, heat transfer and performance of single-phase turbulent flow in spirally corrugated tubes, Exp. Therm. Fluid Sci. 24 (2001) 131-138.

[11] F.T. Akyildiz, D.A. Siginer, L. Khezzar, Energy losses and heat transfer enhancement in transversally corrugated pipes, Int. J. Heat Mass Transf. 54 (2011) 3801-3806.

[12] V. Srinivasan, K. Vafai, R.N. Christensen, Analysis of heat transfer and fluid flow through a 
spirally fluted tube using a porus substrate approach, J. Heat Transfer. 116 (1994) 543-551.

[13] H. Najafi Khaboshan, H.R. Nazif, Investigation of heat transfer and pressure drop of turbulent flow in tubes with successive alternating wall deformation under constant wall temperature boundary conditions, J. Brazilian Soc. Mech. Sci. Eng. 40 (2018) 1-16.

[14] T.M. Lazim, Z.S. Kareem, M.N.M. Jaafar, S. Abdullah, A.F. Abdulwahid, Heat transfer enhancement in spirally corrugated tube, Int. Rev. Model. Simulations. 547 (2014).

[15] P. Forooghi, K. Hooman, Effect of buoyancy on turbulent convection heat transfer in corrugated channels - A numerical study, Int. J. Heat Mass Transf. 64 (2013) 850-862.

[16] N. Tokgoz, M.M. Aksoy, B. Sahin, Investigation of flow characteristics and heat transfer enhancement of corrugated duct geometries, Appl. Therm. Eng. 118 (2017) 518-530.

[17] Z.Y. Guo, D.Y. Li, B.X. Wang, A novel concept for convective heat transfer enhancement, Int. J. Heat Mass Transf. 41 (1998) 2221-2225.

[18] B. Li, B. Feng, Y.L. He, W.Q. Tao, Experimental study on friction factor and numerical simulation on flow and heat transfer in an alternating elliptical axis tube, Appl. Therm. Eng. 26 (2006) 2336-2344.

[19] J.A. Meng, X.G. Liang, Z.J. Chen, Z.X. Li, Experimental study on convective heat transfer in alternating elliptical axis tubes, Exp. Therm. Fluid Sci. 29 (2005) 457-465.

[20] S.K. Saha, Thermohydraulics of turbulent flow through rectangular and square ducts with axial corrugation roughness and twisted-tapes with and without oblique teeth, Exp. Therm. Fluid Sci. 34 (2010) 744-752.

[21] N. Phan-Thien, M.M.K. Khan, Flow of an oldroyd-type fluid through a sinusoidally corrugated tube, J. Nonnewton. Fluid Mech. 24 (1987) 203-220.

[22] S. Mahmud, A.K.M. Sadrul Islam, C.M. Feroz, Flow and heat transfer characteristics inside a wavy tube, Heat Mass Transf. Und Stoffuebertragung. 39 (2003) 387-393.

[23] Z. Cao, J. Xu, D. Sun, J. Xie, F. Xing, Q. Chen, X. Wang, Numerical simulation of modulated heat transfer tube in laminar flow regime, Int. J. Therm. Sci. 75 (2014) 171-183.

[24] W.G. Osley, P. Droegemueller, P. Ellerby, CFD investigation of heat transfer and flow patterns in tube side laminar flow and the potential for enhancement, Chem. Eng. Trans. 35 (2013) 9971002.

[25] S.K. Saha, Thermohydraulics of laminar flow through a circular tube having integral helical corrugations and fitted with helical screw-tape insert, Chem. Eng. Commun. 200 (2013) 418-436.

[26] Z. Grant Mills, T. Shah, A. Warey, S. Balestrino, A. Alexeev, Onset of unsteady flow in wavy walled channels at low Reynolds number, Phys. Fluids. 26 (2014).

[27] P.G. Vicente, A. García, A. Viedma, Mixed convection heat transfer and isothermal pressure drop in corrugated tubes for laminar and transition flow, Int. Commun. Heat Mass Transf. 31 (2004) $651-662$.

[28] A. Zachár, Analysis of coiled-tube heat exchangers to improve heat transfer rate with spirally corrugated wall, Int. J. Heat Mass Transf. 53 (2010) 3928-3939.

[29] E. Jantsch, Tubular heat transfer aparatus, 2663321, 1953.

[30] K. Navickaite, D. Noel, K. Engelbrecht, C. Bahl, Passive heat transfer enhancement in 3D corrugated tube, in: 9th World Conf. Exp. Heat Transf. Fluid Mech. Thermodyn., Foz do Iguaçu, Brazil, 2017: pp. 3-5.

[31] S. V. Patankar, C.H. Liu, E.M. Sparrow, Fully developed flow and heat transfer in ducts having streamwise-periodic variations of cross-sectional area, J. Heat Transfer. 99 (1977) 180.

[32] J. Hærvig, T. Condra, K. Sørensen, Numerical investigation of single-phase fully developed heat transfer and pressure loss in spirally corrugated tubes, in: 56th SIMS, 2015: pp. 391-397. 